\title{
Guest Editorial: A Note on the Notion of Commercialism
}

\author{
ALBERT R. JONSEN
}

The essays in this Special Section are about the ethics of Commercialism in Medicine. They are written, for the most part, by bioethicists, with the support of several prominent physicians and a health policy lawyer. This journal is, of course, devoted to ethics. Thus, our intent is to subject the question of commercialism in medicine to ethical scrutiny. Much has been written about commercialism in healthcare but very little about the ethics of commercialism in healthcare. One of our authors, Dr. Jerome Kassirer, has encouraged a national dialogue about these issues. We hope to start that dialogue in the bioethical community and, through that community, into the nation.

This opening essay is a prefatory note that states the theme of the Section, attempts some definition of the terms "commerce" and "commercialism," and reviews the principal questions with which our authors deal. The Section proper opens with two essays written from the viewpoint of two leading participants and observers of medicine in modern America, both former editors of the New England Journal of Medicine. First, Dr. Arnold S. Relman states the theme of our Section, the problem of a medicine that has become enmeshed in commercialism. In the next essay, Dr. Jerome Kassirer, author of On the Take: How Medicine's Complicity with Big Business Can Endanger Your Health, presents a picture of commercialism in contemporary medicine. ${ }^{1}$ Then Professor Marc A. Rodwin explains how recent health policy and health law have encouraged commercialism. There follow six essays written by bioethicists; two of whom are philosophers and four are practicing physicians. The bioethicists' essays were written after two 2-day meetings at the Program in Medicine and Human Values of the California Pacific Medical Center in San Francisco. Professor Jacob Needleman, a philosopher who has written books about the practice of medicine and the meaning of money, sat through these discussions and offers some concluding philosophical reflections. It is important to note that when we say "philosophical reflections" we do not mean ethereal musings. Dr. Needleman intends his reflections to provide the essential questions of the national dialogue that Dr. Kassirer encourages.

The dialogue should begin, as Socrates showed centuries ago, with an attempt to define the terms. "Commerce" is, in itself, a neutral term. We have a Department of Commerce, chambers of commerce, commercial paper, and laws about interstate commerce. Most words ending in "ism" have an air of

Special thanks to J. Westly McGaughey for his editorial assistance in preparing this collection of papers. 


\section{Guest Editorial}

mystery about them, referring often to ideologies, sometimes unpleasant ones. Commercialism, then, must imply something unusual about commerce, possible something unacceptable. So, these notes are a short treatise on the meaning of our terms, at least as we use them in these essays. These notes are not a minitreatise on economics. I am not an economist (as anyone who is adept at economics will tell me). I am an ethicist, wading into tides that may wash me away. However, this tentative dip into economics must be made in order to pursue the objective of these essays, namely, to show how commercialism and medicine relate to each other in moral terms. In our culture, medicine has, for the most part, been a commercial activity (except when monks were its practitioners) and has, as such, always presented moral problems. When medicine gets as deep into commerce as it is today, its very moral stature is submerged. We hope to suggest how and why.

I want the spirit of Adam Smith to preside over this note, for he was both a moral philosopher and the father of modern economics. He was the author of the seminal treatise on commerce in his Wealth of Nations (1776). He was also the professor of moral philosophy at University of Glasgow. He paid little attention to medicine, but his description and analysis of political economy provides an unprecedented view of the nature and working of commerce that might illuminate our efforts. Wealth of Nations reminds us that "The propensity to truck, barter and exchange one thing for another ... is common to all men, and to be found in no other race of animals" (p. 1). ${ }^{2}$ The Oxford English Dictionary offers this quaint definition: Commerce is "the exchange between men of the products of nature or art" (p. 552). ${ }^{3}$ The ability to create these "products of nature and art," to transform them into an infinite collection of desirable things, to transport and trade them makes for commerce. The coming together of people with products to trade makes a market. So commerce is always with us, not only common to but probably inherent in human intercourse.

The products of nature and art have been named "commodities." In simplest form, commodities appear in any market as distinct, packaged products, able to be displayed, priced, and carted off by the buyer. Of course, commerce can also be carried on by exchange of titles, interests, and shares and packaged in virtual as well as paper boxes. In addition to commodities, modern commerce also sells services, less tangible than commodities but more flexible in forms of delivery and pricing. Today, many services are "packaged" as commodities, given the appearance of a distinct thing that can be put on display and advertised in some concrete way. A recent news story tells that people are giving gifts of cosmetic surgery to their friends and family. Boyfriend pays the surgeon $\$ 10,000$ and girlfriend gets a card saying she has a nose job waiting. Our question is whether the service called medicine can be, or should be, commodified, whether commodification erodes, in some significant way, the practice of medicine. Dr. William Andereck's essay addresses the commodification of medical practice.

A market in which commerce is carried on requires more than the physical space in the middle of a village. It requires ways and means to effect tradinghawking, soliciting, bargaining, dealing. The grower of apples must not only get them to the market; he must attract attention to his stall, polish his apples, and tout them as bigger and more flavorsome than the others being offered. Far from the peddling of fruit, the global markets of today employ similar but 
vastly more sophisticated ways and means to place their product before buyers. Adam Smith says "man has almost constant occasion for the help of his brethren and it is vain for him to expect it from their benevolence only. He will be more likely to prevail if he can interest their self-love in his favour, and shew them that it is for their own advantage to do for him what he requires of them" (p. 20). ${ }^{4}$ All the ways and means of marketing are, in essence, solicitations of self-love. The central place of self-interest in Smith's economic theory is well known. It reflects his basic thesis in moral philosophy, explained in his Theory of Moral Sentiments. The philosophical theory is now reinforced by centuries of business experience and by empirical data about the psychology of motivation and market decisions (soon to be verified by the findings of neuroscience). The ways and means of interesting self-love, whether as simple as a clever "pitch" or a sexy ad or complex as the negotiations leading to a multibillion dollar merger, constitute what we mean by "commercialism" in these essays.

The Oxford English Dictionary defines "commercialism" as "the principles and practice of commerce" (p. 553)..$^{5}$ Defined in this way, commercialism is little more than the subject matter of a business school textbook. It is what is taught to those who wish to enter commerce of any sort. It explains how to establish a market and move products in ways that make profit. Those ways and means range from the stapling of a sign, "Lemonade $5 \not{ }^{\prime \prime}$ to a tree to a million dollar advertising budget. They are devised by a couple of guys in a garage or the big brains at Disney or Harvard Business School or Enron. They are carried out from the basket of a bicycle or by global corporations of gigantic scope. In themselves, these principles and practices, these ways and means, are morally neutral.

However, the ways and means of commerce always involve communication and thus enter the realm of the moral issues about truth telling. Does, can, should advertising tell the truth? Also, the techniques of interesting self-love may entail, as Adam Smith says, "every servile and fawning attention to obtain their good will" (p. 20). ${ }^{6}$ Not only is truth embellished, but vendors must convince customers that they are deeply, sincerely interested in them and their welfare, thereby winning not only their interest but their trust, a trust that exists only to promote the sale. The "principles and practice" of commerce can explain how to manipulate and exploit persons, corporations, and communities. A vendor may or may not employ these means, but they are "in the book." Enron was following the "principles" of commerce by using techniques available to everyone who does commerce but, fortunately, repudiated by many. Every technique of commercialism is subject to moral scrutiny. Our question is whether the incorporation of medicine into commerce and the application to it of the "principles and practice of commerce" is a right and good thing-the essential moral question. Dr. Lawrence J. Schneiderman's essay addresses the ways in which publicity and advertising present the work of medicine.

None of these principles and practices of commerce is particularly pejorative in itself. But the American Heritage Dictionary hints at a possibly pejorative meaning of commerce: "an attitude that emphasizes tangible profit or success" (p. 267). ${ }^{7}$ Commerce as barter presumably exchanges commodities of roughly equal value. However, as the earliest swappers learned, value is in the eye of the beholder, and the vendor can pump up the desire of the customer to have 


\section{Guest Editorial}

the item and to give more for it than an equitable exchange. Medieval moralists scorned any form of profit as "usury," seeing it as unjust exchange. That moral scruple is long gone. Markets of every sort ensure that desires for their products have been pumped up by publicity. Consumers have a range of choices; they have the freedom to select. It is the merchandiser's job to focus the interest and emotion on his commodity. In a peculiar irony, bioethics has worked to enhance the autonomy of patients, yet it is autonomy that opens up the range of choice to which commercialism can appeal. Dr. Jonathan D. Moreno's essay analyzes this irony.

The emphasis on "tangible profit or success" is, again, not itself evil. It is, however, the beginning of absorption of all valuing into monetary terms. The desire to sell implies the desire to profit. Estimates of profit require that all elements that enter into the production and marketing of a commodity or service be expressed in monetary terms. Profit can contribute to the growth and improvement of the business. It can also enrich its owners and expand their power. As commerce itself extends throughout a society, so does money become the single scale of value and success? Our question is whether this form of universal value is compatible with medicine. This is the theme of Dr. Larry R. Churchill's essay on the hegemony of money.

Commerce is carried on in markets where humans meet to "truck, barter and exchange." The ancient market was a place in the center of town; the modern market is virtual and global, without boundaries and without shops. Its activities, spirit, and attitudes creep into every aspect of life. In our culture, it has been thought right that there be market-free zones where, although interchanges between humans take place, monetary exchanges are forbidden. The courts and the Congress and the church are the most prominent of the market-free places but there are many others, family, education, etc. The standards of value in market-free zones are distinct and appropriate to their activities: justice, the common good, the salvation of the soul. Of course, the immunity of these market-free zones is often violated, but, in principle, they maintain sanctity of a sort. We readily recognize violation and find it shameful.

Again, Adam Smith helps us frame the issue. He writes, "It is not from the benevolence of the butcher, the brewer, or the baker, that we expect our dinner, but from their regard to their own interest. We address ourselves, not to their humanity, but to their self-love, and never talk to them of our own necessities but of their advantages. Nobody but a beggar chuses to depend chiefly upon the benevolence of his fellow-citizens" (p. 20). ${ }^{8}$ Yet, for centuries, the ethics of medicine has insisted that benevolence should motivate the physician. What is it about the practice of medicine that makes it different from the work of butcher, brewer, and baker? Can we really expect there to be more than a little benevolence in medical practice? Is it to protect this benevolence that we want medicine to be, in some essential way, a market-free zone? How does the clinic differ from the market? Can physicians stand in both worlds, medicine and commerce, or does this involve inevitable conflicts of interest? Dr. Joseph J. Fins is charged to give an answer to these questions.

This note has attempted a rough definition of "commerce" and "commercialism." It has suggested that at several points, the intersection of medicine and commerce requires moral scrutiny: the production of a commodity, the means 


\section{Guest Editorial}

of marketing the commodity, and the attitude toward profit from commodities. Our questions are whether medicine should be considered a product that can be traded, and thus, commercial, whether the methods devised to carry out commerce are suited to medicine, and whether and how attitudes relating to profit affect medicine. We are seeking to understand the ways in which the practice of medicine fit into the world of commerce. More importantly, we wish to understand whether commerce and commercialism are compatible with the essential goals and work of medicine.

We see these questions not only as searches for answers that are empirical and descriptive. These essays are not, in essence, sociological or economic ones. They are, we think, moral questions. Our bioethical authors explain why they conceive of these questions as moral ones. Also, the reflections of bioethicists conclude with judgments that certain actions or institutions are right and good or wrong and evil. Such judgments do not, in themselves, reform those actions or reconstruct those institutions. Others who participate and hold power within them must undertake change. Bioethicists may argue that commercialism is wrong for medicine, but physicians, politicians, patients, and the public must act to extricate medicine from commercialism.

The essays in this Special Section do not assert that medicine should be free of commerce or even commercialism, in its more innocuous sense of methods that make commerce go. Medicine has been commerce since its appearance in western culture. Hellenic physicians took money for their medical advice. They were warned, in one Hippocratic saying, "Sometimes give your services for nothing. . . . If there be an opportunity of serving a stranger in financial straits, give full assistance" (p. 299). ${ }^{9}$ Plato commented on the problem of medical commerce. In the opening pages of The Republic, he questions his audience about how to distinguish the goals of various activities. Physicians, he notes, accept money for engaging in healing. Should medicine then be called business? This would be silly, he says, because a physician can do the work of healing even if he does not take money for it. Medicine has one goal; business has another. ${ }^{10}$ Plato's concern about mixing medicine and money making echoes through the history of medicine. Another great moralist, Thomas Aquinas, notes that the Christian physician must care for the poor but that obligation is not so strict as to prevent him from making a living. ${ }^{11}$ Treatises on medical ethics raise the issue again and again. One prominent medical moralist of the Middle Ages writes, "you must treat the poor free for the love of God; you may make the rich pay dearly" (p. 20). ${ }^{12}$

Physicians have always been involved with money and sometimes have placed money above their duties to patients. Physicians have often been poor but some have become very rich at their patients' expense. Today, some physicians have enthusiastically embraced commercialism. Some simply cannot imagine medicine as anything other than commercial and wonder what the fuss is about. Other physicians, while disliking the constraints and moral compromises involved in commercialism, comply with them because the system seems overwhelming and inevitable. Others try in various ways to extricate themselves from the web. However, these essays are about much more than the connivance or complicity of physicians with commercialism. They are about the culture of commercialism that has engulfed medicine and, in the view of our authors, compromised its moral foundations. 


\section{Guest Editorial}

\section{Notes}

1. Kassirer J. On the Take. How Medicine's Complicity with Big Business Can Endanger Your Health. New York: Oxford University Press; 2005.

2. Smith A. An Inquiry into the Nature and Causes of the Wealth of Nations. New York: Collier and Son; 1909.

3. The Compact Oxford English Dictionary. $2^{\text {nd }}$ ed. Oxford: Clarendon Press; 1991.

4. See note 2, Smith 1909:20.

5. See note 3, Compact Oxford 1991:553.

6. See note 2, Smith 1909:20.

7. The American Heritage Dictionary of the English Language. Boston: Houghton Mifflin; 1973.

8. See note 2, Smith 1909:20.

9. Hippocrates. Trans. WHS Jones. Cambridge, Mass.: Harvard University Press: 1923.

10. Plato. The Republic. In The Dialogues of Plato. Trans. B Jowett. New York: Random House; I, 346.

11. Aquinas T. Summa Theologiae. Latin text and English translation. New York: McGraw-Hill; 1964:II-II, 71.7.

12. de Mondeville H. On the Morals and Etiquette of Surgeons. London: Kegan Paul, Trench, Trubner and Co.; 1910. 


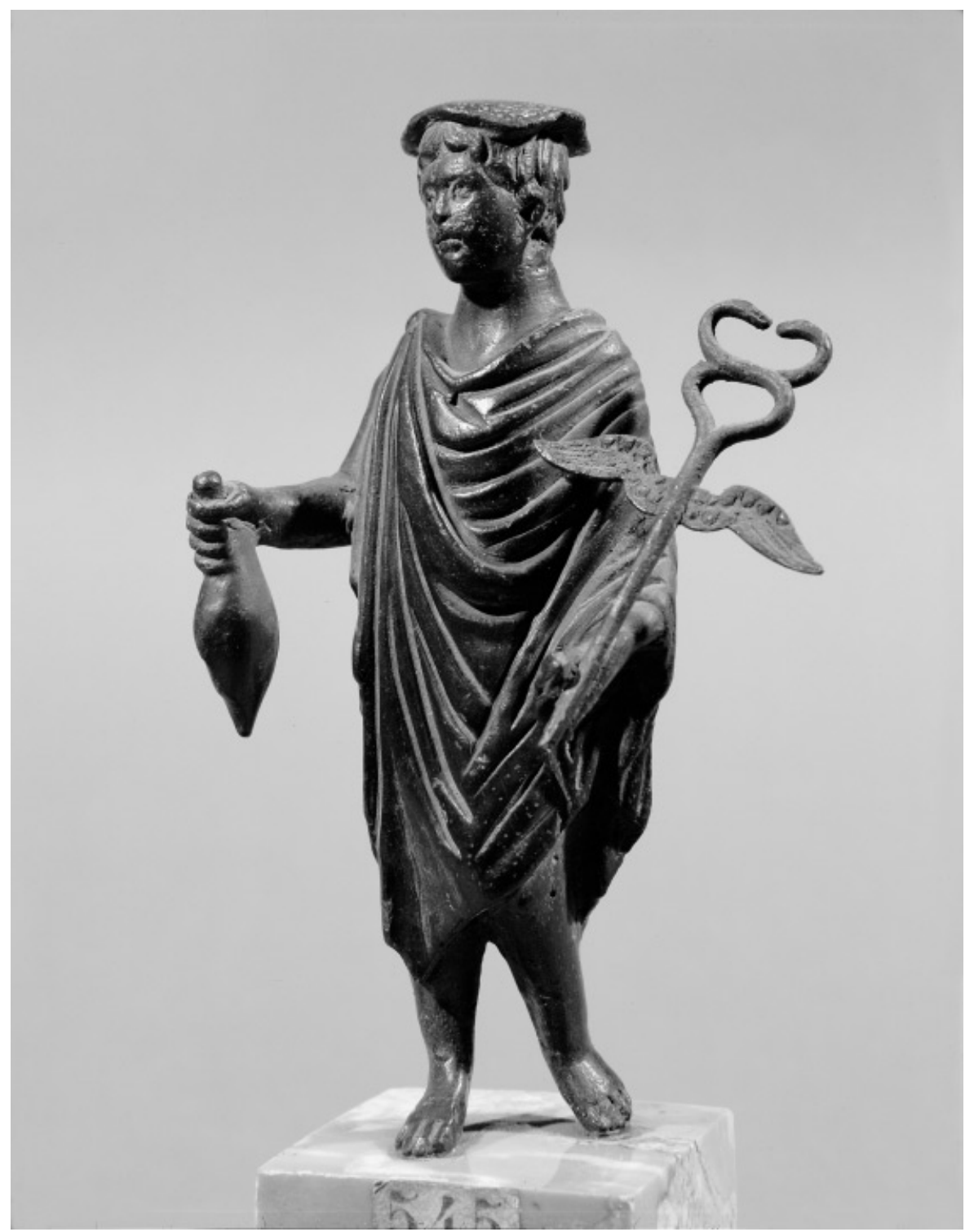

God Hermes with staff and money bag. Bronze (fourth century BCE). Louvre, Paris, France. Photo credit: Erich Lessing/Art Resources, New York. Reproduced by permission. 